\title{
New method for allocating high-speed railway infrastructure costs among train types
}

\author{
Chao $\mathrm{Ji}^{1,}{ }^{*}$, Chenyu $\mathrm{Xu}^{1}$ \\ ${ }^{1}$ School of Economics and Management, Beijing Jiaotong University, 100044, Beijing, China.
}

\begin{abstract}
With the rapid development of China's high-speed railway (HSR), there are also many problems. For example, in the classification and calculation of HSR transportation costs, there is a lack of reasonable cost statistical methods. There are many types of high-speed train currently running on HSR (mainly G and $\mathrm{D}$ trains). There are differences in the speed, load and energy consumption of different types of trains. The resulting infrastructure usage costs also vary. However, all train costs are classified and calculated uniformly in practice. This paper proposes the expenditure rate method of the transport process allocating the infrastructure use costs among types of trains. Based on data from the Beijing-Shanghai high-speed railway, the cost of infrastructure is calculated, and the calculation results can reasonably reflect the cost allocation among types of trains. It makes the cost calculation of high-speed railway more accurate and lays a foundation for environmental cost calculation.
\end{abstract}

\section{Introduction}

The management and operation of the railways have been under the responsibility of the CHINA RAILWAY (CR) for many years. This situation has led to the drawbacks of a market monopoly and a lack of competitiveness in the railway transportation industry. The reason is mainly due to the lagging reform of the management system of China's railway industry and the inaccurate calculation of cost classification.

This article conducts research from three aspects: the first is the reform policy, which proposes that the future reform direction of China's railway is vertical separation; The second is the solution. A new method of expenditure rate calculation is proposed for overcoming the problem of inaccurate cost classification statistics. The expenditure rate method is used to solve the cost allocation problem of HSR with various types of trains. Finally, the proposed solution is applied to the BeijingShanghai HSR to evaluate the rationality of the cost allocation. The research results can provide an exploration path for the cost allocation estimation of China's HSR.

\section{Reform}

Based on international experience in railway reform and restructuring, the separation of the railway infrastructure and operations is inevitable [1]. European railway practice proves that the separation of network transportation is an alternative direction for the reform of the railway transportation management system. After the separation of the railway network and transportation, it is helpful to distinguish the management responsible for the railway network from that responsible for passenger and cargo operations and to obtain accounting and operational data on the statistical costs from various operational departments.

The European Commission has been asking member states to adopt a vertical separation model [2]. Sweden, the United Kingdom and Germany have been using railway infrastructure charging systems for the longest and have extensive experience [3]. They separate the railway network infrastructure, which has a natural monopoly, from the competitive rail passenger and cargo transportation, thereby providing open-access policies for new entrants. The railway operator has added another entity (infrastructure manager) for charging infrastructure users [4].

In the more than ten years of separation of European railways, many scholars have studied the railway infrastructure charges of Germany [5], the United Kingdom [6], France [7], Netherlands [8], Sweden [9], Italy [4], Bulgaria [10] and other countries. The International Union of Railways [11] also presents an overview of the structure of the European toll system and explores differences among the countries.

Infrastructure charges cannot be separated from the calculation of railway transportation costs. The calculation principles of railway transportation cost including the marginal cost (MC), full cost (FC), full cost minus ( $\left.\mathrm{FC}^{-}\right)$, marginal cost plus mark-up $(\mathrm{MC}+)$ and marginal cost + Ramsey (MC + Ramsey) principles.

Based on the economic principles of railway transportation cost calculation, considerable literature has studied on the factors affecting transportation cost allocation. Line types [12], train weight [13], crowding factors [14], incentive regulatory mechanisms [15],

\footnotetext{
*Corresponding author: j.i.chao@163.com
} 
environmental costs [16], maintenance and update costs [17], multimodal transport [18] and other cost components have also been thoroughly studied. These factors are applied to complex econometric models to determine the cost function of the infrastructure.

However, many cost-based calculation models do not reflect all the costs that are incurred by train operations, and other theoretical models have a single application environment. These factors are not shortcomings of the models; they are mainly due to the differences in the policies and actual operations of each country. Most of the above methods perform well for small- and mediumsized railway networks, but they are not suitable for such a large road network environment as that in China.

\section{Methods}

\subsection{Expenditure rate method of the transport operation process}

In contrast to traditional cost methods, the operation process cost method has the following characteristics: the basic cost calculation object is the transport operation process, which is the basis for summarizing other costs. The distribution and collection of indirect costs are considered, and the operation cost database is constructed. To reflect the characteristics of diversity, the cost allocation criteria are determined, which are the cost drivers. The process of cost generation is considered, the product cost result assessment is changed to the process evaluation of the operational cost, and the monitoring of the production cost process is strengthened. This type of calculation method has been widely used, and it is expressed as a sub-item of the transportation operation process in the calculation of the railway cost in China. This method can be used to calculate the railway transportation cost; however, limitations remain on the cost allocation calculation of the railway train types. It is not possible to refine the cost according to the train type; hence, it is expanded on the basis of the operation costing method, and the railway cost is calculated via the transportation process expenditure rate method.

The evaluation method for the transportation operation process can be used to calculate and analyze the variable cost of railway transportation based on the expenditure rates of various operational indicators. For various costs, such as the operating cost of the rolling stock, the cost of the shunting operation, and the transportation cost of the section, it is also possible to analyze the impacts of various measures and various transportation expenditures on the transportation cost and to solve the train cost allocation problems on the sub-line. This is the most suitable method for solving the train cost allocation problems on the subline.

The expenditure rate method can calculate and analyze the variable cost of railway transportation based on the expenditure rates of various operational indicators. We combine the expenditure rate method with the China railway transport operation process sub-item to obtain the separate expenditure rate method. This method uses the strategies and steps of the transportation process subitem to calculate the railway cost in the form of the expenditure rate method. The calculation process is illustrated in Fig 1.

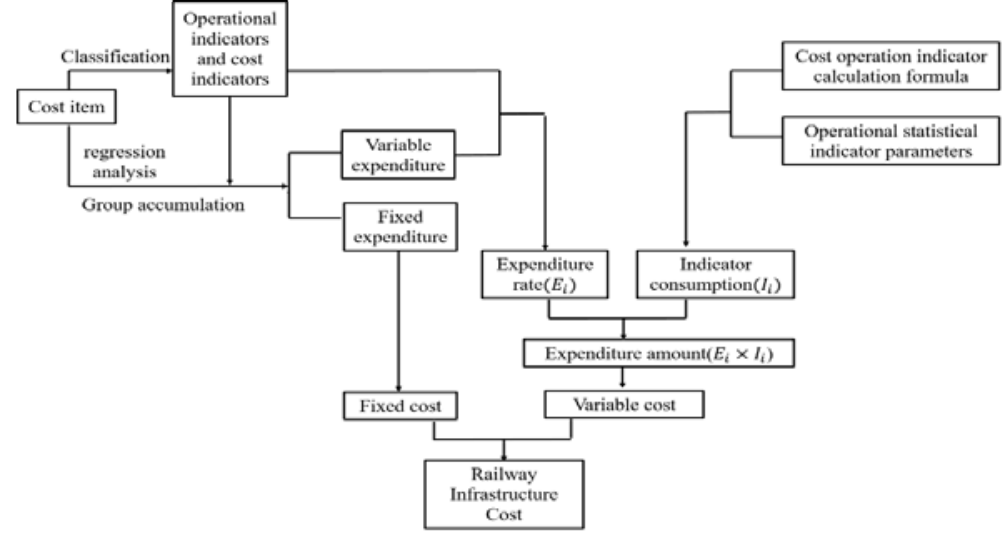

Figure 1. Calculation process of the expenditure rate method

\subsection{Application of the expenditure rate}

\subsubsection{Expenditure rates can be used to predict the cost of shipping for a specified amount of work.}

For completing the specified workload, the consumption of each indicator is $\mathrm{Q} \omega$, and the actual variable cost $\mathrm{c}$ of an indicator is:

where:

$$
V C_{\omega}=\beta_{\omega} \times Q_{\omega}
$$

$\mathrm{VC} \omega$ the variable cost of completing the specified workload $\beta \omega$ the expenditure rate of indicator $\omega$

Q $\omega$ the consumption of the specified workload indicator $\omega$

For normal investment decisions and operational decisions, only long-term changes in transportation products can be calculated. Considering the need for full-cost analysis, including the fixed costs, in practical applications such as profit and loss analysis, a method is provided for calculating the fixed costs using a fixed percentage of the fixed expenditure.

$$
\mathrm{P}_{\mathrm{FC}}=\left(\mathrm{C} / \sum_{\omega=1}^{7} V C_{\omega}\right)-1
$$




$$
F C=\mathrm{P}_{\mathrm{FC}} \times \sum_{\omega=1}^{7} V C_{\omega}
$$

where:

$\omega \quad$ the number of operational indicators (this paper selects a value from 1 to 7 )

PFC proportion of the fixed costs

$\mathrm{C}$ total transportation expenditure

$\mathrm{VC} \omega$ total variable cost of the specified workload

FC fixed costs

After calculating the variable cost of each indicator, the variable costs are summed, and the fixed cost FC is used to obtain the total cost $\mathrm{C}$ of the railway train that has completed the specified workload. The calculation formula is:

$$
C=\sum_{\omega=1}^{7} V C_{\omega}+F C
$$

\subsubsection{Using the regression results of the expenditure rate to calculate the expenditure rate of each indicator in other years.}

Assuming that there are cost and workload data for years $\mathrm{n} 1$ to $\mathrm{n} 2$, the expenditure rate of each indicator has been obtained via the above method. If the cost data and workload data of year $\mathrm{nt}+1$ are obtained, the expenditure rate of each index of year $\mathrm{nt}+1$ can be calculated.

If the data time span was sufficient, all linear regression models were used for the regression analysis. The regression equation model is:

$$
\mathrm{Y} \omega \mathrm{i}=\mathrm{a} \omega \mathrm{i}+\mathrm{b} \omega \mathrm{i} \times \mathrm{X} \omega \mathrm{i}
$$

where:

Ywi the amount of the i-th cost item that is collected in the expenditure rate indicator $\omega$

a $\omega \mathrm{i}$ the fixed cost of the i-th cost item in the expenditure rate indicator $\omega$

boi the expenditure rate of the $i$-th cost item in the expenditure rate indicator $\omega$

$\mathrm{X} \omega \mathrm{i}$ the workload that corresponds to the $\mathrm{i}$-th cost item in the expenditure rate indicator $\omega$

$\omega \quad$ a value from 1 to 7

The rate of change of the i-th cost item can be obtained:

$$
\alpha \mathrm{i}=(\mathrm{bi} \times \mathrm{Xi}) /(\mathrm{ai}+\mathrm{bi} \times \mathrm{Xi})
$$

where $\alpha \mathrm{i}$ is the rate of change of the $\mathrm{i}$-th cost item. The rate of change refers to the proportion of the variable costs in this cost item.

where:

$$
\beta \omega \mathrm{t}+1=i\left[\left(Y_{i_{t+1}} \times \alpha_{i}\right) / X_{i_{t+1}}\right]
$$

$\beta \omega t+1$ the expenditure rate of indicator $\omega$ in year $t+1$

$Y_{i_{t+1}} \quad$ the i-th cost item that is collected in indicator $\omega$ in year $\mathrm{t}+1$

$X_{i_{t+1}}$ the workload that corresponds to the i-th cost item of indicator $\omega$ in year $t+1$

By using the rate of change of each cost item in the previous year that has been calculated, it is possible to directly divide the variable cost in the following years. It is easier to use the data directly for regression. The changes in recent years can be combined with the selection. Rate data are used to prevent large errors in the calculation results due to outdated data.

\section{Cost data and calculation}

\subsection{Background}

This paper uses the operating cost data of BeijingShanghai high-speed railway (abbreviated as the Jinghu HSR) to calculate the allocation cost of the railway infrastructure. The main line of the Jinghu HSR is 1,318 kilometers long. The whole line is a new double line and is approximately the same as the original Jinghu HSR. The target speed is $380 \mathrm{~km} / \mathrm{h}$. The CRH380 is the main model. In the operating scenario, the maximum operating speeds are $300 \mathrm{~km} / \mathrm{h}$ for the G-Series highspeed train (hereinafter called G-EMU) and $200 \mathrm{~km} / \mathrm{h}$ for the D-Series high-speed train (hereinafter called DEMU). The number of trains that depart from Shanghai Hongqiao Station has increased from 7 to 8 pairs since April 2018. From 8:00 am to 19:00 pm, there are trains running at all times except for 11:00, 13:00 and 16:00. According to the data of the Railway Customer Service Center, a total of 41 pairs of trains are operated between Beijing and Shanghai. Among them, there are 40 pairs of high-speed trains (G-EMU) and one pair of D-EMU trains.

\subsection{Expenditure rate indicator system}

Since China began to apply a unified railway transportation cost expense report in the railway system in 2015, the time span was insufficient, and related subjects were changed before and after the report reform. When calculating the expenditure rate, the method of replacing the regression coefficient by the average value is used to obtain the total change in expenditure and the corresponding workload to an indicator; then, the expenditure rate of the operational indicator is calculated. If the time span for the latter calculation is sufficiently long, the regression method can be used to calculate a more accurate indicator expenditure rate.

The calculation formula for the expenditure rate of each operational indicator is as follows:

$$
\beta_{\omega}=\overline{V C}_{\omega} / \bar{Q}_{\omega}
$$

where $\beta \omega$ is the expenditure rate of a specified indicator, $\overline{V C}_{\omega}$ and $\bar{Q}_{\omega}$ are the average values of the relevant subject expenditures and consumption indicators for each indicator over the years, and $\omega$ refers to each indicator in the operation indicator system table, which can take a value from 1 to 7 .

The average cost collection results and the expenditure rates of various indicators from 2015 to 2017 are presented in Table 1. 
Table 1. Jinghu HSR transportation operation expenditure rate

\begin{tabular}{|c|r|r|r|}
\hline $\begin{array}{c}\text { Indicator } \\
\text { name }\end{array}$ & $\begin{array}{c}\text { Cost item } \\
\text { (million } \\
\text { yuan) }\end{array}$ & $\begin{array}{c}\text { Workload } \\
\text { (million) }\end{array}$ & $\begin{array}{c}\text { Expenditure } \\
\text { rate }\end{array}$ \\
\hline $\begin{array}{c}\text { Number of } \\
\text { passengers } \\
\text { dispatched }\end{array}$ & 842.41 & 199.64 & 4.2197 \\
\hline $\begin{array}{c}\text { Train } \\
\text { kilometers }\end{array}$ & 4724.34 & 39.45 & 119.7619 \\
\hline Train hours & 2633.53 & 0.17 & 15739.1176 \\
\hline $\begin{array}{c}\text { Electricity } \\
\text { consumed } \\
\text { by train } \\
\text { operation }\end{array}$ & 2760.00 & 3852.93 & 0.7163 \\
\hline $\begin{array}{c}\text { Train crew } \\
\text { hours }\end{array}$ & 427.05 & 0.20 & 2126.8545 \\
\hline $\begin{array}{c}\text { Locomotive } \\
\text { crew hours }\end{array}$ & 106.77 & 0.18 & 580.0785 \\
\hline $\begin{array}{c}\text { Train gross } \\
\text { tonnage } \\
\text { kilometers }\end{array}$ & 1462.59 & 25641.03 & 0.0570 \\
\hline
\end{tabular}

\subsection{Train sub-type expenditure rate indicator correction}

According to the number of trains, the trains are divided into G-EMU and D-EMU. Among the 41 trains of Beijing-Shanghai high-speed trains, 40 pairs are G-EMU and 1 pair of D-EMU, which account for $85.8 \%$ and $7.6 \%$.

According to the above, the correction coefficient of the Jinghu HSR train type indicator expenditure rate is obtained via calculation and is presented in Table 2.

Table 2. Beijing-Shanghai high-speed train type expenditure rate correction factor table

\begin{tabular}{|c|l|r|r|}
\hline \multirow{2}{*}{$\begin{array}{c}\text { Indicator } \\
\text { name }\end{array}$} & Apportionment standard & Correction factors \\
\cline { 3 - 4 } & G-EMU & $\begin{array}{c}\text { D- } \\
\text { EMU }\end{array}$ \\
\hline $\begin{array}{c}\text { Number of } \\
\text { passengers } \\
\text { dispatched }\end{array}$ & $\begin{array}{l}\text { Ratio of the number of } \\
\text { passengers }\end{array}$ & 0.93 & 0.07 \\
\hline $\begin{array}{c}\text { Train } \\
\text { kilometers }\end{array}$ & Ratio of the train kilometers & 0.98 & 0.02 \\
\hline Train hours & Ratio of the train hours & 0.97 & 0.03 \\
\hline $\begin{array}{c}\text { Electricity } \\
\text { consumed by } \\
\text { train } \\
\text { operation }\end{array}$ & $\begin{array}{l}\text { Ratio of the electricity that } \\
\text { is consumed by train }\end{array}$ & 0.97 & 0.03 \\
\hline $\begin{array}{c}\text { Train crew } \\
\text { hours }\end{array}$ & $\begin{array}{l}\text { Ratio of the train crew } \\
\text { hours }\end{array}$ & 0.97 & 0.03 \\
\hline $\begin{array}{c}\text { Locomotive } \\
\text { crew hours }\end{array}$ & $\begin{array}{l}\text { Ratio of the locomotive } \\
\text { crew hours }\end{array}$ & 0.97 & 0.03 \\
\hline $\begin{array}{c}\text { Train gross } \\
\text { tonnage } \\
\text { kilometers }\end{array}$ & $\begin{array}{l}\text { Ratio of the train gross } \\
\text { tonnage kilometers }\end{array}$ & 0.98 & 0.02 \\
\hline
\end{tabular}

\subsection{Train type cost calculation}

According to the calculation results of the train type expenditure rate correction factor in Table 2. The annual average costs of passenger transport for the BeijingShanghai high-speed rail from 2015 to 2017 for the two train types are:

\section{G-EMU $V C_{\mathrm{G}}=12.595$ billion yuan}

D-EMU $V C_{\mathrm{D}}=361$ million yuan

The average transportation expenditure of the Beijing-Shanghai high-speed rail from 2015 to 2017 is approximately 16.6 billion yuan. According to the cost collection, the total variable cost is 12.956 billion yuan, and the fixed cost is 3.644 billion yuan. According to the train-type fixed cost allocation formula, the fixed costs are:

G-EMU FCG $=3.644 \times(12.595 / 12.956)$ billion yuan

$=3.542$ billion yuan

D-EMU FCD $=102$ million yuan

Therefore, considering the fixed costs, the passenger transport costs of Beijing-Shanghai high-speed railway are calculated via the expenditure rate method as:

Approximately 12.595 billion yuan (excluding the fixed costs) and 16.137 billion yuan (including the fixed costs) for G-EMU.

Approximately 361 million yuan (excluding the fixed costs) and 463 million yuan (including the fixed costs) for the D-EMU.

\section{Conclusions and future research}

Based on the principle of cost pricing, a system based on the expenditure rate method covers all operating costs, thereby ensuring that road network operators can maintain a low profit and encourage efforts to reduce costs. The calculated cost allocation results for two types of trains on the Beijing-Shanghai high-speed railway agree with the actual costs. According to this method, the various cost types (classified according to carriage and freight, train speed, train weight, and driving density) are calculated for the two train types on the railway line, and the impact degree of each factor on the charging system can also be calculated. The infrastructure charging system that is based on this method is suitable for large railway networks.

The main shortcoming of this paper is that China Railway Corporation began to apply the unified railway transportation cost project in 2015; hence, relevant data were unavailable. Therefore, it is relatively simple to calculate the expenditure rate. The correct rate of change is not obtained via regression analysis, and the average value can only be calculated via analogy analysis. The indicator expenditure rate that is obtained by calculating the annual transportation cost is temporary. With the rapid development and vertical separation reform of the railway, its operation has reached a mature stage and the relevant data have been further improved. At this time, the correction calculation results can be modified to make the cost data more accurate and standardized. The high-speed rail cost calculation method proposed in this paper can be extended to other railway lines for estimating the cost of other types of trains on other railway lines. 


\section{References}

1. F Jørgensen, H Pedersen, G Solvoll. Ramsey Pricing in Practice: the Case of the Norwegian Ferries. Transport Policy 11, (2004), pp. 205-214

2. C.A. Nash, M. Finger, T. Holvad (Eds.). Rail transport. Regulating transport in Europe, Edward Elgar, Cheltenham, UK, Northampton, MA, USA (2013)

3. Mirjana Bugarinovic, Branislav Boskovic. A systems approach to access charges in unbundling railways. European Journal of Operational Research 240 ,3 (2015), pp. 848-860

4. Francesco Rotoli, Eva Valeri, Stefano Ricci, Luca Rizzetto, Gabriele Malavasi. An analysis of the railway access charges regime in the Italian context. Transport Policy, 64 (2018), pp. 20-28

5. H. Link. Railway infrastructure charging and on Track competition in Germany. International Journal of Transport Management 2, 1 (2004), pp. 17-27

6. C. Nash, S. Coulthard, B.Matthews. Rail track charges in Great Britain the issue of charging for capacity. Transport Policy 11, (2004), pp. 315-327

7. Sánchez-Borràs, M., López-Pita, A. et al., 2008. Rail infrastructure charges: how to convert them into a tool for strengthening international highperformance railway passenger services. In: Proceedings of the 8th World Congress on Railway Research (WCRR 2008).

8. Daniel van Vuuren. Optimal pricing in railway passenger transport: theory and practice in The Netherlands. Transport Policy 9, (2002), pp. 95-106

9. Kristofer Odolinski. Contract design and performance of railway maintenance: Effects of incentive intensity and performance incentive schemes. Economics of Transportation 18, (2019), pp. 50-59

10. Christina Nikolova. User charges for the railway infrastructure in Bulgaria. Transportation Research Part A 42, (2008), pp. 487-502

11. UIC.Track Access Charges in EU. Railway Costing \& Pricing, Paris (2015)

12. M.T. Claessens, N.M. van Dijk, P.J. Zwaneveld. Cost optimal allocation of rail passenger lines. European Journal of Operational Research 110, 3 (1998), pp. 474-489

13. Mirjana Bugarinovic, Branislav Boskovic. A systems approach to access charges in unbundling railways. European Journal of Operational Research 240 , (2015), pp. 848-860

14. John Dodgson, Bertil Hylen. An Examination of Rail Infrastructure Charges. Statensvag--och transport for skningsinstims, 5 (1998), pp. 2-7

15. T. Coelli, A. Estache, S.Perelman, L. Trujillo. A Primer on Efficiency Measurement for Utilities and Transport Regulators. The World Bank, Washington D.C, (2003)
16. P. Bickel, R. Friedrich, H. Link, C. Nash. Introducing environmental externalities into transport pricing: measurement and implications. Transport Reviews 26, 4 (2005), pp. 389-415

17. M. Andersson, A. Smith, A.Wikberg, P. Wheat. Estimating the marginal cost of railway track renewals using corner solution models. Transportation Research Part A 46, 6 (2012), pp. 954-964

18. Cornelia Gremm. The effect of intermodal competition on the pricing behaviour of a railway company: Evidence from the German case. Research in Transportation Economics 72, (2018), pp. 49-64 